\title{
Novel Turbocharger Concept and Control Strategy for Diesel Passenger Car
}

\author{
J.Shekaina \\ Research Scholar \\ Dr. M.G.R Educational and Research Institute \\ Chennai, TamilNadu, India
}

\author{
T. Jayasingh \\ Dean \\ C.S.I Institute of Technology \\ Thovalai, TamilNadu, India
}

\begin{abstract}
In a modern small sized passenger car fitted with a common rail diesel engine, turbo-lag is an important factor which hampers its performance. This paper discusses the basics of turbo-charger and VGT and some of the methods employed to reduce the turbo-lag in CRDI diesel engine. A novel turbocharger concept, approach to design, the control strategy and advantages of the concept are explained.
\end{abstract}

\section{Keywords}

Common Rail Direct Injection, Turbo lag, Supercharger, Variable Geometry Turbocharger, Air - fuel ratio.

\section{INTRODUCTION}

In automotive applications, the driver of the vehicle who operates the vehicle, the road in which the vehicle is operated upon also becomes part of the system. Thus, improvement in drivability, reduction in fuel consumption and exhaust emissions are prime concerns while improving the system and designing the control strategy. And, increasing the high end power output doesn't make any difference to the drivability of the vehicle at low speeds. Low end response at high load transient conditions is needed for improving drivability. Also, decrease in fuel consumption does not necessarily reduce toxic emissions. So, reducing turbo lag and maintaining the desirable air-fuel ratio will address the mentioned criteria. A novel turbocharger concept has been developed to reduce turbo lag by adding a hydraulic turbine to the conventional VGT. By this design good acceleration response can be achieved even when accelerating from low speed, high load conditions.

\section{TURBO CHARGING AND ITS EFFECTS ON THE POWER OUTPUT}

In a naturally aspirated diesel engine about $30 \%$ of the heat energy of the diesel combusted is wasted in the exhaust gases. By letting the exhaust gases to expand in the turbine wanes of the turbocharger part of this wasted energy is recovered and converted into useful work by the compressor fitted with the turbine shaft. The outlet of the compressor is connected to the inlet manifold via an inter-cooler to increase the density of the air flowing into the inlet manifold. With no additional energy spent, the turbocharger is able to increase the volumetric efficiency of the diesel engine. The power output of the engine increases without much addition in the weight of the engine with the same displacement volume. When operating at high speed high load conditions, as the quantity of exhaust gases are more, the turbocharger supplies more air to the inlet manifold. When operating at high speed low load condition, as lesser fuel is injected the quantity of exhaust gases is less, the turbocharger supplies less air to the inlet manifold, thereby reducing the energy spent on the compression of air inside the cylinder which is good for low load condition. The formation of nitrous oxide is also reduced in these conditions because of the lower temperatures in the combustion chamber. But the problem arises when the engine is required to be accelerated from low speeds, the response is far from desirable. Under this condition, the exhaust gas available in the turbine chamber is less and hence the turbine and compressor impellers are spinning are lower speeds. Increasing the power output when torque demand is more at lower engine speeds is a task. Engines fitted with fixed geometry turbocharger (FGT), just struggle to increase the power output in the transient conditions [1]. Increasing the quantity of fuel injected without out increasing the air intake will lead to unburnt fuel and soot in exhaust. The delay in acceleration response is turbo lag.

\section{VGT AND ITS FUNCTION}

Variable geometry turbocharger perform better because when the torque demand is more at low engine speeds, the geometry of turbine is varied in such a fashion to increase the velocity of exhaust gases hitting the turbine wanes. The speed of the turbine increases and more quantity of air is made available to the inlet manifold. Eventually, the power output increases. However, it cannot match the torque demand in all conditions, particularly when abrupt acceleration is needed. The block diagram of air circuit is given below.

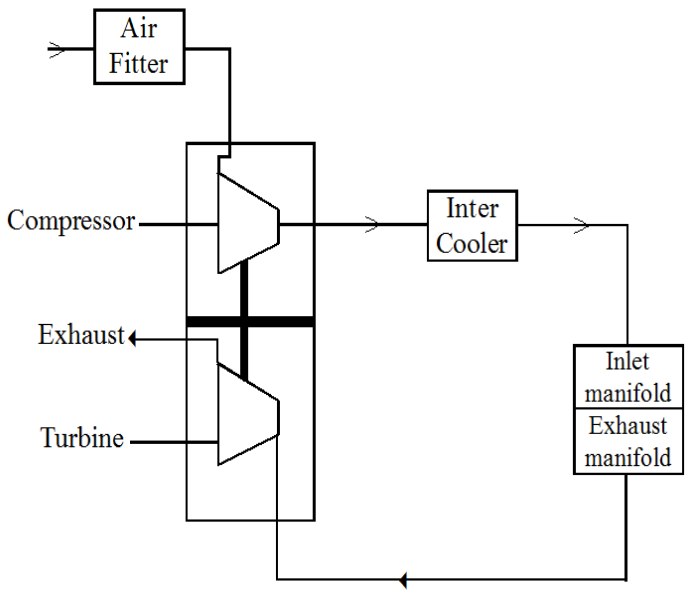

Fig 1: Block diagram of air circuit 


\section{ANALYSIS OF EXISTING METHODS FOR CONTROLLING TURBO LAG}

\subsection{Electric Super Charging}

In Electric super charging, the electric supercharger is connected in parallel to the turbocharger of the CRDI engine [2]. The turbocharger is commanded to increase the speed from $5000 \mathrm{rpm}$ to about $70000 \mathrm{rpm}$ when acceleration is required, which is achieved in about $1 / 3 \mathrm{rd}$ of a second. [3]. Here the turbo lag is reduced by injecting air into the inlet manifold [4]. In this method the turbo lag was found to be reduced from about four seconds to less than one second. The disadvantages of electric super charging is, it requires about 350 amps of 12 volt DC current for achieving this high speed within a short time. A normal battery fitted in a Car powered by 1 to 2 lt. CRDI engine cannot support this supercharger. An additional Li-Al battery or a series of lead acid batteries are needed for the purpose which could pose additional mass and cost problem for a small / medium size passenger vehicle.

\subsection{Power Assist system}

In another method turbocharger power assist system (TPAS), a permanent magnet synchronous motor is attached to the turbocharger to create the model turbo electric assist system [TEA] [1]. The system has been able to improve acceleration performance, reduce turbo lag, reduce soot emissions and improve fuel economy [5-11]. Based on this principle Mitsubishi Heavy. Industries have designed a hybrid turbo charger and tested in a 2 litre engine. It increased the efficiency to $8-12 \%$ [12] and reduced the turbo lag from 4 $\mathrm{sec}$ to $1.3 \mathrm{sec}$. The disadvantages of TEA system is, it requires as 72 volt battery whereas the passenger cars are normally fitted with a 12 volt battery. Further research and development should be carried out in many areas related to this concept that could lead to a viable product for small/medium passenger car applications.

\section{PROPOSED VGT ANDCONTROL STRATEGY}
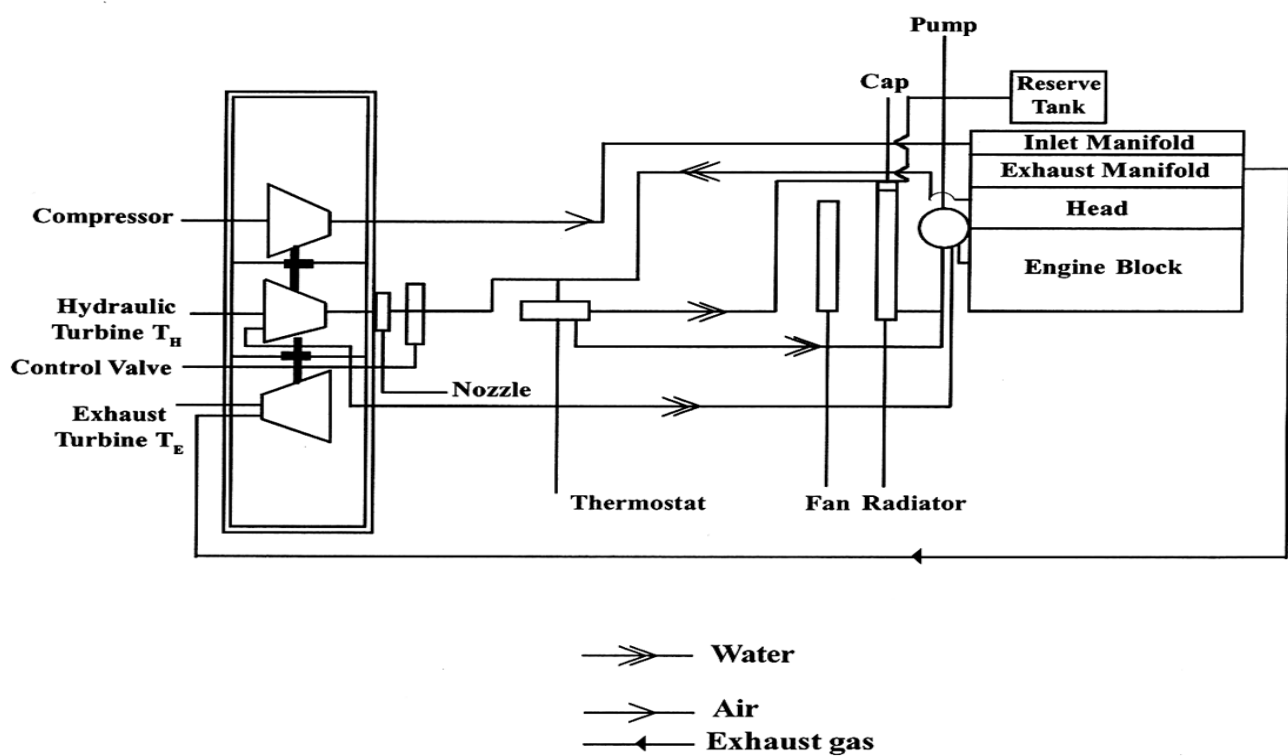

Fig 2: Block diagram of proposed VGT

As shown above an additional chamber is added to the regular VGT design. The third chamber consists of a turbine $T_{H}$ fitted in series to the turbo shaft of the VGT. This turbine is driven by the kinetic head of an external hydraulic circuit. The turbine chamber houses a set of inlet nozzle(s) to speed up the turbine $T_{H}$ when more output is required at the compressor outlet and the second set of nozzles to slow down the turbine when condition dictate reduction of compressor output. The working of this turbine $T_{H}$ is similar to that of the turbine $T_{E}$ that is present in the VGT. The turbine $\mathrm{T}_{\mathrm{E}}$ is made to spin by the expansion of the exhaust gases, whereas the turbine $T_{H}$ is energized by the drop of the velocity head of the fluid impinging the rotor of $T_{H}$. As both the turbine rotors have the same axis and fitted to the same shaft, the rotors of both the turbines have the same rpm.

When high pressure and high velocity fluid is directed to the impeller of turbine $T_{H}$ by the inlet nozzles, the speed of its impeller increases, thereby increasing the speed of turbine $T_{E}$ and the centrifugal compressor. The fluid used to increase the speed of $\mathrm{T}_{\mathrm{H}}$ is the coolant; which is a mixture of antifreeze like ethylene glycol and water directed from the engine cooling system. About a third of the heat energy of fuel is transferred to the ambient by the coolant used in the system. Due to the heat transferred from the engine during operation the temperature and pressure of the coolant increases. The pressure is maintained at high level to increase the boiling point of the coolant. As the water pump is used in the system for circulating the coolant, the coolant also possesses kinetic energy.

In the proposed VGT design the coolant at high velocity and pressure is used to drive the turbine $T_{H}$ in order to accelerate from low speed high load conditions. The coolant system consists of the following components: radiator, electrical fan, water pump, reserve tank, thermostat, pressure cap and hoses.

A coolant pump which is directly coupled to the engine circulates coolant in the system. Whenever the engine is in 
operation, the coolant pump circulates the fluid to the passages inside the engine block and head [13]. The heated coolant coming out of the engine head flows to the thermostat. The thermostat bypasses the coolant to the pump till the temperature reaches the set value. Once the set value is reached the thermostat opens the passage to the radiator and directs the coolant through the upper hose of the radiator. The heated coolant flows through the radiator and dissipates the excess heat and flows to the pump through the lower radiator hose[14]. The radiator cap fitted in the top of the radiator maintains a set pressure to the fluid inside the system. When running at high temperature, the excess fluid released through an opening near the radiator cap, gets stored in a reserve tank. When the coolant temperature falls down the fluid returns to the radiator.

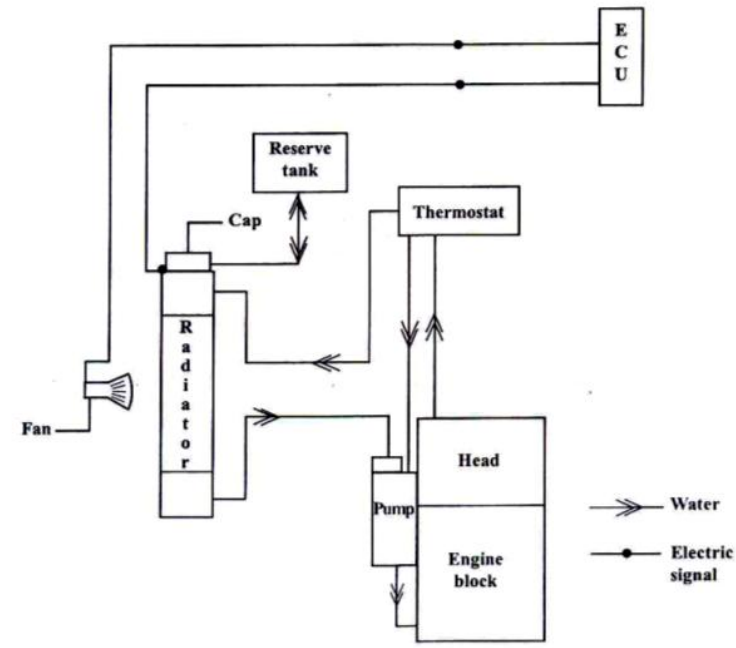

Fig 3: Cooling system of engine

In the proposed design of VGT, the fluid flowing out of the engine head to the thermostat is utilized to energize the turbine $\mathrm{T}_{\mathrm{H}}$ when accelerating from low speed high load conditions. A hose is connected from the hose leading to the thermostat, to the control value of the fluid circuit leading to $\mathrm{T}_{\mathrm{H}}$. During operating condition, high pressure fluid is readily made available to the direction control valve near the nozzle set of $\mathrm{T}_{\mathrm{H}}$. The opening and closing of the control value of $\mathrm{T}_{\mathrm{H}}$ is dictated by the ECU of the engine. When additional boost is required to accelerate the engine, the ECU orders the change in aspect ratio of the VGT. When conditions dictate extra boost, it also orders the opening of the inlet nozzle set of $T_{H}$ so as to direct the high pressure fluid to the $T_{H}$ impeller. As the coolant passes through the nozzles, the velocity of the fluid increases and impinges the rotor with good force. This action increases the speed of $\mathrm{T}_{\mathrm{H}}$ and thereby increases the output of the compressor.

As more air is made available to the inlet manifold of the engine, the power output increases and the exhaust gas quantity also increases. This in turn accelerates the turbine $\mathrm{T}_{\mathrm{E}}$.

When this condition is reached, the ECU orders the control valve to stop supplying the fluid to $\mathrm{T}_{\mathrm{H}}$. During conditions when the torque demand is low and the compressor output is more, the ECU orders the opening of valve leading to the set of nozzles which aids in reducing the speed of turbine $\mathrm{T}_{\mathrm{H}}$ and thereby reducing the compressor output.

\section{APPROACH TO DESIGN OF THE MODIFIED VGT}

Turbo shaft:

The length of the shaft can be increased to accommodate the third rotor and its housing. The same diameter and the material which has been already used for the reference VGT can be selected.

\section{Bearing:}

Fluid bearings that are normally used in the reference VGT can be selected for the modified version also, because both the designs perform the same kind of operations.

Impellers:

The same impellers used for the compressor and turbine $T_{E}$ (exhaust) sections can be selected. The third impeller $T_{H}$ has to designed based on the power required to increase the output of the compressor at turbo lag conditions.

Consider the engine operating at low speed of $1000 \mathrm{rpm}$. For a $1300 \mathrm{cc}$ engine and compressor output of $1.1 \mathrm{bar}$.

Volume of air consumed by the engine $=$

$$
\begin{aligned}
& \frac{1000}{2} \times 1.300 \times 10^{-3} \mathrm{~m}^{3} / \mathrm{min} \\
& =0.65 \mathrm{~m}^{3} / \mathrm{min} \\
& \mathrm{PV}=\mathrm{nRT} \\
& \mathrm{n}=\mathrm{PV} \\
& \mathrm{RT} \\
& \mathrm{n}=\text { mass of air } \\
& \mathrm{P}=\text { pressure } \\
& \mathrm{V}=\text { volume } \\
& \mathrm{R}=\text { gas constant } \\
& \mathrm{T}=\text { Temperature in Kelvin } \\
& \mathrm{n}=\frac{1.1 \times 10^{-5} \times 0.65}{} \\
& =0.75 \mathrm{~kg} / \mathrm{min} \\
& =0.0125 \mathrm{~kg} / \mathrm{sec}
\end{aligned}
$$

Specific work done by the compressor to overcome turbo lag.

Assume P1 = 1.1 bar

$\mathrm{P} 2=1.4 \mathrm{bar}$

$\mathrm{T}=60^{\circ} \mathrm{C}$

Specific work

$\mathrm{W}=\left(\frac{\mathrm{K}}{\mathrm{K}-1}\right) \mathrm{RT}\left[\left(\frac{\mathrm{P}_{2}}{\mathrm{P}_{1}}\right)^{\frac{\mathrm{K}}{\mathrm{K}-1}}-1\right]$

$\mathrm{W}=\frac{1.4}{1.4-1} \times 286.9 \times 333 \times\left[(1.272)^{0.2857}-1\right]$

$\mathrm{W}=23406 \mathrm{Nm}$ 
Hence additional work done to overcome the turbo lag for the specification and the condition of the reference engine is

$\mathrm{W}=23406 \times .0125 \mathrm{Nm}$.

$=293 \mathrm{Nm}$

The design of turbine $T_{H}$ should be of impulse type. The turgo turbine will most likely match the requirements; because in the turbine $T_{H}$ we intend to convert the velocity head of the coolant into useful work. In impulse turbines, there is no change in the pressure head. For calculation purpose we are ignoring the pressure head, the potential head and the heat energy of the coolant. Hence

$$
\frac{V_{\text {inlet }}^{2}}{2}=\frac{\mathrm{V}_{\text {outlet }}^{2}}{2}+\mathrm{W}_{\text {shaft }}+\mathrm{W}_{\text {loss }}
$$

The reference engine is a 1.3 liter CRDI diesel engine mentioned previously. Its power output is $94 \mathrm{bhp}$ at $4000 \mathrm{rpm}$. Assume the power output at $1000 \mathrm{rpm}$ is

$\frac{94}{4000} \times 1000$

The quantity of coolant circulated is calculated depending on the heat output of the reference engine. Assume thermal efficiency as 23 percentage and energy lost to coolant as 32 percentage.

Therefore,

total energy lost to

coolant at $1000 \mathrm{rpm}=24 \mathrm{kw}$.

$\mathrm{Q}=\mathrm{m} \times \mathrm{C}_{\mathrm{P}} \times \Delta \mathrm{T}$

$\mathrm{Q}=24 \mathrm{kw}=24 \mathrm{KJ} / \mathrm{sec}$.

$\mathrm{C}_{\mathrm{P}}=4.183 \mathrm{KJ} / \mathrm{sec}$.

$\Delta \mathrm{T}=50$ (Temperature difference)

$24=\mathrm{m} \times 4.183 \times 50$

$\mathrm{m}=\frac{24}{50 \times 4.183}$

$=0.115 \mathrm{~kg} / \mathrm{sec}$

The hose diameter of cooling system $=3.5 \mathrm{~cm}$

Delivery at $1000 \mathrm{rpm}=0.115 \mathrm{Kg} / \mathrm{sec}$.

Volume of coolant circulator at

$1000 \mathrm{rpm}=\mathrm{V}=\frac{m}{\rho}$

$\rho_{\text {water }}=1000 \mathrm{~kg} / \mathrm{m}^{3}$

$\rho_{\text {ethylene glycol }}=800 \mathrm{~kg} / \mathrm{m}^{3}$

Assume 50:50 concentration.

Density of coolant, $=900 \mathrm{~kg} / \mathrm{m}^{3}$

$\mathrm{m}=0.115 \mathrm{~kg} / \mathrm{sec}$.

Volume V $=\frac{0.115}{900}$

$\mathrm{V}=1.3 \times 10-4 \mathrm{~m}^{3} / \mathrm{sec}$.
The diameter of hose $=3.5 \mathrm{~cm}$.

Velocity at hose $\mathrm{V}_{\mathrm{h}}=\frac{\text { volume }}{\text { area }}$

$\mathrm{V}_{\mathrm{h}}=\frac{1.3 \times 10^{-4}}{0.00097}$

$=0.134 \mathrm{~ms}-1$

Diameter of nozzle $=0.12 \mathrm{~cm}$

Velocity at nozzle $V_{n}=115 \mathrm{~ms}^{-1}$

Specific work done at $\mathrm{T}_{\mathrm{H}}=\frac{115 \times 115}{2}-\frac{5 \times 5}{2}$

$=6612-12.5 \mathrm{Nm}$

$=6600 \mathrm{Nm}$

Assume turbine efficiency as $90 \%$ for turgo turbine

Work done at the turbine

$\mathrm{W}_{\text {Shaft }}=$ specific work done $\mathrm{x}$ mass $\mathrm{x}$ efficiency of turbine

$=683 \mathrm{Nm}$

From this calculation we can safely assume that about 43 percentage of the circulating coolant from the cooling system is sufficient to accelerate the turbine $T_{H}$ for desired output.

The pressure and velocity of the fluid available in the cooling system varies depending on the operating conditions. As the additional work to be done to reduce turbo lag is known, the velocity and quantity of the coolant flowing to the rotor $\mathrm{T}_{\mathrm{H}}$ can be changed, the rotor and nozzle can be designed to meet the demands. The energy recovered to meet the demand will be proportional the quantity of the fluid flowing into $T_{H}$ and the drop in velocity head across the turbine. With appropriate design of the runner some of the heat energy present in the coolant can also be converted into useful work.[16].

As many as 56 dimensional values [15] define the rotor and simulation should be carried out with sophisticated software for defining the dimensions which is beyond the scope of this paper.

\section{CONCLUSION}

As the design of the modified VGT is based on existing technologies, the cost and time required to develop the product is minimal. The additional power required to overcome the turbo lag is generated from the engine cooling system. Recovery of part of the energy normally wasted into the ambient is also envisaged. Although the cost of the proposed VGT increases with the additional $\mathrm{T}_{\mathrm{H}}$, while mass producing; the additional costs incurred will more than be compensated. The acceleration and deceleration characteristics and overall efficiency would improve.

\section{REFERENCES}

[1] Glenn B. C, Upadhyay D, washington G.N, 2010,Volume 18, issue 4, "Control Design of Electrically assisted Boosting systems for Diesel power train applications" control systems technology, IEEE Transactions.

[2] Shimizu, Koupi, Aniyamoto, Taashi-2010" Engine with super charger "-U.S. Patent application 20100236531.

[3] Julian Edgar,2010, "Is this your electric super charger?”,Technical features issue : 582 
[4] Gikes.O.S, Oliver.S - Dec 2010"Computer simulation of air injection to inlet manifold on turbo charged engine " F2006 SC 35.

[5] Algrain.M and Hopmann.U, 2003, "Diesel Engine Waste Heat Recovery Utilizing Electric Turbo Compound Technology," in Proc. DEER Conf.

[6] Shahed.S.M , "Smart Boosting Systems E-Turbo And ECharger New Frontier?," presented at the U.S. DOE DEER Workshop Portsmouth, VA, Aug. 2001.

[7] Arnold.S, Balis.C, Poix.E, Samad.T, and Shahed.S.M, "Design and development of an e-Turbo for SUV and light truck applications," presented at the DEER Conf. San Diego, CA, Aug.2004.

[8] Kolmanovsk.I, Stefanopoulou.A.G, and Powell.B.K , "Improving turbocharged diesel engine operation with turbo power assist system," in Proc. IEEE Int. Conf. Control Appl., HI, 1999, pp. 454-459.

[9] Kolmanovsky.I and Stefanopoulou.A , "Optimal control techniques for assessing feasibility and defining subsystem level requirements: An automotive case study," IEEE Trans. Control Syst. Technol., vol. 9, no.3, pp. 524-534, May 2001
[10] Upadhyay.D and Rizzoni.G , "Engine systems: Lubrication, wear,components, system dynamics, and design," Amer. Soc. Mechan. Eng.,Internal Combustion Engine Div. (Publication) ICE, vol. 36, no. 3,pp. 69-83, 2001.

[11] T. Katrasnik, S. Rodman, F. Trenc, A. Hribernik, and V. Medica, "Improvement of the dynamic characteristic of an automotive engine by a turbocharger assisted by an electric motor," ASME J. Eng. for Gas Turbines Power, vol. 125, pp. 590-595, Apr. 2003.

[12] Sellchi Baraki , Yokho Yamashita, Kuniosumida, Hirashiogita, Yasuaki Jinnai Sep 2006 Mitsubishi Heavy Industries Ltd Techanical ReviewVol. 43, No.3 "Development Of The Hybrid Turbo An Electrically Assisted Turbo Charges"

[13] C-1 2006, Smart Trac Computer systems Inc.

[14] Flexxaire: Total airflow Comtrol: www.flexxaire.com

[15] Diamerkuper - 2009 Turbocharger design \& performance analysis GTS Inc.

[16] Infinity Turbine -Organic Rankine Cycle ORC. Waste Heat Turbine and Geothermal www.infinityturbine.com 